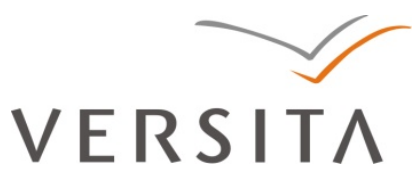

BULGARIAN ACADEMY OF SCIENCES

CYBERNETICS AND INFORMATION TECHNOLOGIES • Volume 13, Special Issue

Sofia • 2013

Print ISSN: 1311-9702; Online ISSN: 1314-4081

DOI: 10.2478/cait-2013-0042

\title{
Synergic Relationship and Synergic Degree between an Information System and Corporate Strategy
}

\author{
Xie Xiang, Guan Zhongliang, Wang Xiaoliang, Liu Jiashi \\ School of Economics and Management, Beijing Jiaotong University, 100044 Beijing, China \\ Emails:xxie@bjtu.edu.cn_zlguan@bjtu.edu.cn wxlyouth@163.com13113128@bjtu.edu.cn
}

\begin{abstract}
With the development of information technology, the Information System (IS) has not the characters of rareness and inimitability, so an IS cannot form core competence alone. Forming synergic relationship and keeping higher synergic degree between IS and corporate strategy will help the enterprises acquire competence advantage and realize IS value. This paper analyzes the conditions of forming synergic relationship between an IS and strategy, and points out that the key factors for a synergic degree are the strategy rationality and the matching degree between the IS and strategy. Based on the analysis result and BCG growth share matrix, this paper constructed a synergy degree measure model to evaluate the synergic relationship between the IS and corporate strategy. Finally, a case study is used to verify the feasibility of the model.
\end{abstract}

Keywords: Information System (IS), corporate strategy, synergic relationship, BCG Growth Share Matrix, synergy degree.

\section{Introduction}

According to Core Competence, if enterprises need to form the core ability and generate a value advantage, they must have resources which have four basic characters: value, rareness, inimitability and non-substitutability [2]. With the development of information technology, an Information System (IS) has not the characters of rareness and inimitability, so the IS cannot form core competence alone. So, forming a synergic relationship and keeping higher synergic degree between an IS and corporate strategy will help the enterprises to acquire competence advantage and realize IS value contribution to the competitive advantage [4]. 
The corporate strategy is the program or scheme designed to achieve a variety of specific goals for self-development. That is to say, the enterprises choose the right business fields and products, form their own core competitiveness and win in the competition according to the environmental change, their own resources and strength [5]. Corporate strategic resource reflects the enterprises' strategic management capacity, and it plays an extremely important role in the improvement of the core competence to strengthen the management of corporate strategy $[8,9$, 11, 12]. IS and IT are seen as the most important strategic tools increasing the corporate responsiveness and enhanced performance [3]. But the barriers of integrating IS with other systems are also the main hindrance for companies that have no plan to adopt IS [10]. So, in order to realize the IS value, IS should and could form synergic relationship with corporate strategy to support the transformation of the strategy, promote the implementation of the strategy, and ensure the enterprise movement forward in the right direction. T a $\mathrm{ll}$ o n, K e n n e and $\mathrm{G} \mathrm{u} \mathrm{r} \mathrm{b} \mathrm{a} \mathrm{x} \mathrm{z} \mathrm{n} \mathrm{i} \mathrm{[6]} \mathrm{also} \mathrm{expressly} \mathrm{pointed} \mathrm{out} \mathrm{that} \mathrm{better} \mathrm{integration} \mathrm{between} \mathrm{IT}$ and business strategy will bring a higher return on IT investment.

\section{Analysis of synergic relationship between IS and corporate strategy}

Corporate strategy is a strategic system, including competitive strategy, development strategy, technology development strategy, marketing strategy, information technology strategy, talent strategy, as well as other strategies. However, the competition is still a dominant force in the majority of enterprises survival and development, competitive strategy is also the core and the most important content of corporate strategy. So in this paper corporate strategy specifically means competitive strategy and the paper mainly researches the synergic relationship between IS and competitive strategy.

\subsection{Support effect of IS on corporate strategy}

According to Porter's Competitive Strategy Theory, if the enterprises want to be successful in a competitive environment, there are three basic strategies: the costleadership strategy, differentiation strategy and focus strategy. The conditions of implementation of each basic strategy are not the same, so Porter thought that an enterprise had to make a strategic choice if it wants to obtain a relative competitive advantage. The different IS software is able to support these three strategies, and the enterprises can implement a suitable IS based on their chosen strategy.

IS can support the cost-leadership strategy. The prevailing idea of the costleadership strategy is achieving a leadership position in the industry based on a low cost. The basic requirement for this strategy to keep the total cost advantage is reducing the production costs, management costs and transaction costs indefinitely. Because the scope of IS application includes the whole economic activities of the enterprises, it can directly influence the cost of each ring in the enterprise value chain, and thus change and improve the cost structure. IS can reduce the production costs. IS reduces material consumption levels by promoting the technological progress of enterprises, and IS increases labour input by improving the level of 
labour and the value of the human capital. To a certain extent, IS can minimize the cost when the enterprises output is fixed.

IS can support the differentiation strategy. The central idea of the differentiation strategy is to make the products or services provided by the enterprise unique by adding an additional value or distinguishing feature to these products or services, and win overflow price advantage. Because IS can efficiently highlight the technical characteristics, optimize the customer's service, expand the sales network, and promote information multiplication, IS is also able to provide a support for the enterprises to implement a differentiation strategy. For example, IS can improve the efficiency of gaining access to new technologies, new processes, new products and new ideas, accelerate the speed of enterprises restructuring and changes in business strategy, make the enterprises continually provide the market with differentiated products and services, and finally form a unique competitive advantage not easily imitated by competitors. IS enables the enterprises to integrate high development, design, manufacture, marketing and management together, enhance flexibility, agility and adaptability of production, upgrade the industrial production to industrialization lean production, and allows the possibility to provide individual requirement, multi-variety and small batch production and service.

IS can support focus strategy. Focus strategy means that enterprises focus its resources on a particular segmentation market or a particular product, rather than to serve the entire market, and the centralization of the business enables the enterprises to service particular target groups with greater efficiency and better results. The key of the focus strategy is to segment the market and select the appropriate target market. In this way the typical way of IS to support focus strategy is to help the enterprises identify the target market of the products or services and get a return from IS application. For example, the enterprises use IS to collect a lot of customer's data and analyze this data, and determine the main target market of the products or services. Then the main target market is publicized and planned more efficiently and is provided cross service and sales. These type of IS provides the enterprises with information to coordinate the sales and marketing techniques, and bring competitive advantage to the enterprises.

\subsection{Promotive effect of IS on corporate strategic change}

Promotive effect of IS on corporate strategic change behaves as follows: strategy is not considered as a given factor or a constraint factor on the enterprise change; IS is used to impact new products and services, the key strategic attributes and the development of new relationships and corporate strategy can be re-built based on the existing IS. Since the basic characteristics of the corporate strategy includes: global future, systematic, corporate and relative stability, the strategy, once formed, will keep a certain degree of stability in a period of time, of course, sometimes showing a certain lag. IS technology is advancing rapidly, the business environment is also likely to continue to change, therefore, adjusting strategy based on IS is conducive to the development of enterprises. 
2.3. Conditions of forming a synergic relationship between the IS and corporate strategy

IS can support the enterprises to achieve different strategies, so that companies can choose IS applications which are with the highest degree of supporting a corporate strategy determined by the enterprises. Of course, the enterprises can also take advantage of the features and advantages of IS and its related technologies to adjust the corporate strategic goals and play a leading role of IS in strategy. However, because IS technology has a newer rate, if the enterprises develop their corporate strategy based on IS resources, the long-term operation and stability of strategy will not be guaranteed, and the production and operation of the enterprises are also prone to chaos due to the instability of the fundamental objectives. Besides, IS technology is easy to imitate and cannot form the core resources. So corporate strategy, developed entirely based on IS, cannot help the enterprises form core capabilities. Therefore, the key of forming a synergic relationship between an IS and corporate strategy is the supportive effect of IS on strategy rather than the promotive effect of IS on a corporate strategic change. In fact, the fundamental goal of IS application is to support the corporate strategy to be successful, and it is the precondition of the realization of IS value to support the corporate strategy. If IS is deviated from the corporate strategy, no matter how powerful IS function is, the enterprise would never get an IS value, promoting the formation and development of core competencies.

\section{Evaluation of the synergy degree between IS and corporate strategy}

The condition of forming a synergic relationship between an IS and corporate strategy is the support effect of IS on strategy, so the match degree between IS and strategy is the key factor determining the synergy degree. Of course, the suitability of the corporate strategy itself will also affect the synergy degree. Thus, evaluating the synergy degree between IS and strategy must take not into account only the match degree, but also the suitability of a corporate existing strategy.

\subsection{BCG Growth-Share Matrix}

BCG is the acronym for Boston Consulting Group - a general management consulting firm highly respected in business strategy consulting. BCG GrowthShare Matrix happens to be a part of many BCG's strategic concepts that the organization developed in the late 1970-ies [1]. BCG Growth-Share Matrix can assist the enterprises in formulating a corporate strategy by analyzing the validity of the current overall business portfolio of an enterprise. Since business is the specific manifestation of strategy, the suitability of the business portfolio could be considered a direct indicator to measure the suitability of a corporate strategy. That is, the suitability of corporate strategy can be measured by BCG Growth-Share Matrix.

The BCG Growth-Share Matrix is based on two-dimensional variables: a relative market share and market growth. 
The market growth rate is used as a measure of market's attractiveness. Markets experiencing high growth are the ones, where the total market share available is expanding, and there are plenty of opportunities for everyone to make money. The market growth rate is shown on the vertical (y) axis and expressed in percentage. The range is set somewhat arbitrarily. The overhead shows a range of 0 to $20 \%$ with division between low and high growth at $10 \%$ (the original work by B. Headley "Strategy and the Business Portfolio", Long Range Planning, February 1977 used these criteria). When the market growth rate is more than $10 \%$, the market growth means a rapid growth.

The relative market share is used to measure the strength of the enterprise in the relevant business market, which is calculated by the ratio of the market share of a business to the largest market share from competitors. The higher the relative market share is, the higher control power the enterprise has to this business market. The horizontal $(x)$ axis shows the relative market share. Again the range and division between the high and low share is arbitrary. The original work used a scale of 0.1, i.e., the market leadership occurs when the relative market share exceeds 2.0. The BCG Growth-Share Matrix is divided into four cells or quadrants: Stars, Cash Cows, Dogs and Question Marks (Fig. 1). Each of the quadrants represents a particular type of business. The divisions or products are represented by circles. The size of the circle reflects the relative significance of the division/product to group sales. The development of the matrix is used to reflect the relative profit contribution of each division and this is shown as a pie-segment within the circle.

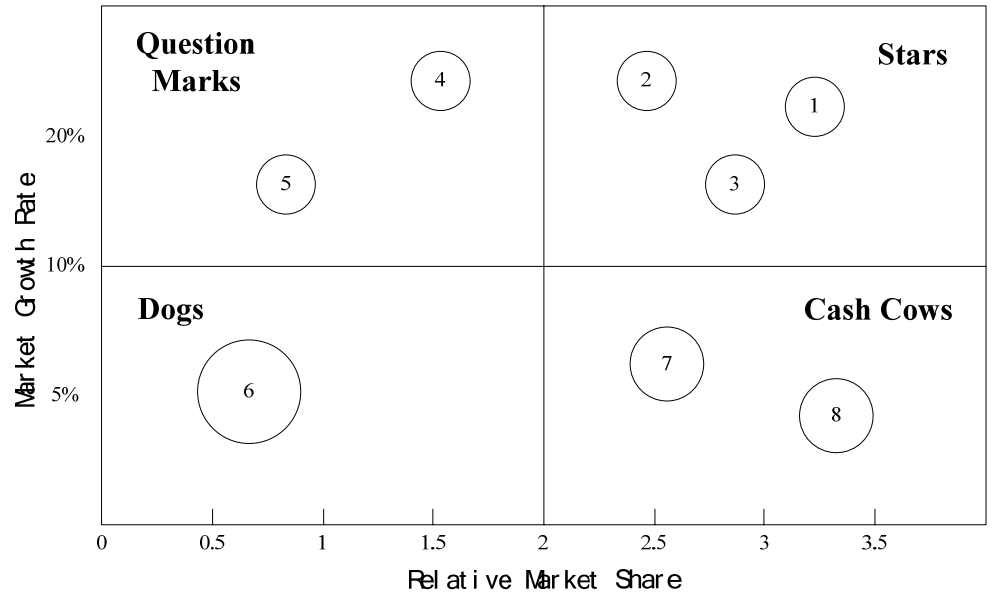

Fig. 1. BCG Growth-Share Matrix

Each type of the business has different characteristics [7].

- Stars are leaders in high growth markets. Stars grow rapidly and therefore use large amounts of cash. Stars also have a high market share and therefore generate large amounts of cash. Over time, the growth of a product will slow. So, if a Star maintains a high market share, it eventually becomes a Cash Cow. If not, it becomes a Dog.

- Cash Cows are highly profitable, and require low investment because they are market leaders in a low-growth market. Growth is slow and therefore cash use is 
low, and the market share is high and therefore cash generation is high. Money generated from cash cows is used to pay dividends, interest, and overheads, and to develop Stars and Question Marks.

- Question Marks are the real cash traps and gambles. Question Marks grow rapidly and therefore use large amounts of cash. However, they do not have a dominant market position and hence do not generate much cash.

- Dogs generate very little cash because of their low market share in a low growth market. BCG refers to these products as cash traps. Although they may be sold profitably in the market, Dogs are net cash users and BCG indicates that, in terms contributing to growth, they are essentially worthless.

Due to the different characteristics of these four businesses, the strategic choice for each business is not the same (shown in Table 1).

Table 1. Strategic guideline of BCG Matrix

\begin{tabular}{|c|c|c|c|c|}
\hline Business type & Profitability & Investment & Net capital flows & Strategy \\
\hline Stars & High & High & $\begin{array}{l}\text { Close to } 0 \text { small } \\
\text { negative number }\end{array}$ & Hold/ Develop \\
\hline Cash Cows & High & High & Big positive number & Hold \\
\hline $\begin{array}{l}\text { Question } \\
\text { Marks }\end{array}$ & $\begin{array}{l}\text { Non or loss } \\
\text { Low or loss }\end{array}$ & $\begin{array}{l}\text { Very high } \\
\text { Recovery }\end{array}$ & $\begin{array}{l}\text { Big negative number } \\
\text { Positive number }\end{array}$ & $\begin{array}{c}\text { Develop, Harvest } \\
\text { /Divest }\end{array}$ \\
\hline Dogs & Low or loss & Recovery & Positive number & Harvest / Divest \\
\hline
\end{tabular}

These available strategies include [12]:

- Develop: The product's market share needs to be increased to strengthen its position. Short-term earnings and profits are forfeited because it is expected that the long-term gains will outweigh these short term costs. This strategy is suited to Question Marks if they are to become Stars.

- Hold: The objective is to maintain the current market share of a product. This strategy is often used for Cash Cows so that they continue to generate large amounts of cash.

- Harvest: Under this strategy, the management attempts to increase the short-term cash flows as far as possible (e.g., by increasing prices and cutting costs) even at the expense of the products long-term future. It is a strategy suited to weak Cash Cows or Cash Cows that are in a market with a limited future. Harvesting is also used for Dogs, and for Question Marks that have no possibility of becoming Stars.

- Divest: The objective of this strategy is to get rid of unprofitable products, or products with a low market share in a low growth market. Money from divestment can then be used to develop and promote more profitable products. This strategy is typically used for Question Marks that will not become Stars and for Dogs.

Based on the analysis of the classified business, the BCG Matrix can enable the enterprises master the basic status of the business, predict changes of future market, and provide the theoretic foundation for the effective distribution of capital investment and reasonable strategy-making. According to BCG Matrix, the suitability of the capital investment portfolio of each business embodies the suitability of the corporate strategy. In other words, the suitability of the corporate 
strategy can be evaluated by analyzing the capital investment portfolio of each business.

\subsection{Evaluation model of the synergy degree between an IS and corporate strategy}

The business is classified into four types according to BCG Matrix, and the business number of Stars, Cash Cow, Question Market and Dogs is each denoted as $N_{1}, N_{2}, N_{3}, N_{4}$. $R_{\mathrm{ij}}$ stands for the $j$-th business belonging to the $i$-th type of business and the range of $i$ is from 1 up to 4 and the range of $j$ is from 0 to $N_{i}$. The sale income and investment is distributed and accumulated, and $S_{i j}$ denotes the total sales revenue of the business $R_{i j}$ in this year, $S_{i j}^{\prime}$ denotes the sales revenue of the business $R_{i j}$ in the last year and $\bar{S}_{i j}$ denotes the total sales revenue of business $R_{i j}$ of the biggest competitors. So,

$$
D_{i j}=\frac{S_{i j}-S_{i j}^{\prime}}{S_{i j}^{\prime}} \times 100 \%,
$$

where $D_{i j}$ is the market growth rate of $R_{i j}$;

$$
M_{i j}=S_{i j} / \bar{S}_{i j}
$$

where $M_{i j}$ is the relative market share of $R_{i j}$;

$$
T_{s}=\sum_{i=1}^{4} \sum_{j=1}^{N_{i}} S_{i j} \text {, }
$$

where $T_{s}$ is the total sales ${ }_{\mathrm{r}}$ evenue of all businesses;

$$
\alpha_{i j}=S_{i j} / T_{s},
$$

where $a_{i j}$ is the proportion of sales revenue of $R_{i j}$.

According to BCG Matrix, Stars businesses and Cash Cows is the source of the sales revenue of businesses, and they are the ultimate fountain of the enterprise survival and development. Since Stars all develop from Question marks, the enterprises should hold a certain proportion of Question Marks. However, the investment risk of the Question Marks is very high, so the proportion of Question Marks in the enterprise is not the higher the better, and the proportion of Question Marks is better to outstrip that of Stars but not exceed the sum of Stars and Cash Cows. Yet, Dogs always can do more harm than good to the enterprises, so the enterprises should reduce the proportion of Dogs as much as possible. Thus, the suitability of corporate strategy $I_{s}$ is denoted by

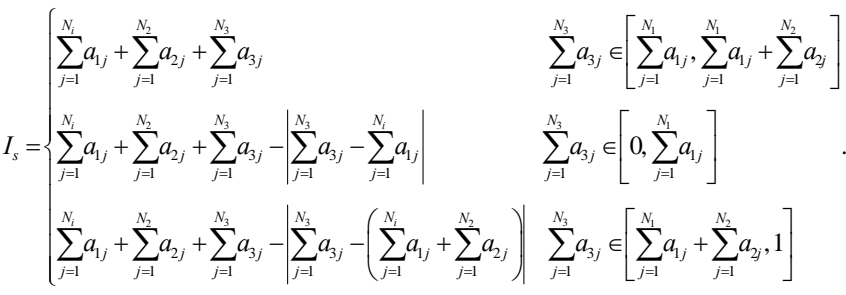


According to BCG Matrix, the market share of the business is higher, and the ability to create profits is greater. The market growth rate of the business is higher, and the enterprise needs more investment to maintain the growth of the business and expand its market share. That is, when the business investment is confirmed, the sale revenue of a business $S_{i j}$ and the market share of the business $D_{i j}$ are directly related; $S_{i j}$ and the market growth rate $M_{i j}$ are negatively related. $S_{\mathrm{ij}}$ is denoted by:

$$
S_{i j}=k \frac{M_{i j}}{1+D_{i j}} \times I_{i j} \text {, }
$$

where $I_{i j}$ is the investment of the enterprise in business $R_{i j}$, and $k$ is a constant coefficient.

By transforming (6), $I_{i j}$ is shown as

$$
I_{i j}=\frac{1+D_{i j}}{k \times M_{i j}} \times S_{i j} .
$$

That equation shows that if $S_{i j}$ is a fixed value, $I_{i j}$ and $M_{i j}$ are negatively related and $I_{i j}$ and $D_{i j}$ are directly related. Based on (7), the desired investment of each business can be calculated, the results of these calculations are summarized, and then the ratio of the desired investment of each business to total investment $\beta_{i j}$ is denoted by

$$
\beta_{i j}=I_{i j} / \sum I_{i j} .
$$

$\beta_{i j}$ shows the investment portfolio of enterprises required by corporate strategy, so the match degree between IS and strategy $F_{s}$ can be defined as the difference between IS investment proportion and business investment proportion $\beta_{i j}$. Support $I_{i j}^{\prime}$ is the IS investment on business $R_{i j}$, then the investment proportion is

$$
\gamma_{i j}=\frac{I_{i j}^{\prime}}{\sum I_{i j}^{\prime}}
$$

and the match degree between IS and strategy of each business type can be defined separately.

Because Stars need high investment to maintain the market share, the IS investment proportion of Stars should increase properly. So the match degree of Stars $F_{s}^{1 j}$ can be calculated by $\gamma_{1 j}-\beta_{1 j}$, and the value of $\gamma_{1 j}-\beta_{1 j}$ is larger and the match degree is higher. In order to make the match degree of a different business additive, the range of $F_{s}^{1}$ must be mapped to [0,1]. Due to $\gamma_{1 j} \in[0,1]$, the match degree of Stars $F_{s}^{1 j}$ is

$$
F_{s}^{1 j}=\left\{\begin{array}{cc}
\frac{1}{2}+\frac{\gamma_{1 j}-\beta_{1 j}}{2 \beta_{1 j}} & \gamma_{1 j} \in\left[0,2 \beta_{1 j}\right] \\
1 & \gamma_{1 j}>2 \beta_{1 j} .
\end{array} \quad \gamma_{1 j} \in[0,1] .\right.
$$

Since Cash Cows have a high market share and generate a stable income to the enterprise, the strategy of Cash Cows is holding its development. So Cash Cows 
investment should maintain a normal level. But increasing excessively its investment will not increase the profits steeply. Therefore, IS investment of Cash Cows $\gamma_{2 j}$ should be approximated to $\beta_{2 j}$ as much as possible, and $\gamma_{2 j}$ greater or less than $\beta_{2 j}$ will reduce the match degree. Thus the match degree of Cash Cows $F_{s}^{2 j}$ is

$$
F_{s}^{2 j}= \begin{cases}1-\frac{\left|\gamma_{2 j}-\beta_{2 j}\right|}{\beta_{2 j}}, & \gamma_{2 j} \in\left[0,2 \beta_{2 j}\right], \\ 0, & \gamma_{2 j}>2 \beta_{2 j} .\end{cases}
$$

The market share of Question Marks is not high, but the market growth rate is high. So increasing the Question Marks investment properly will favour the transformation of Question Marks to Stars, and the IS investment proportion of Question Marks should also increase properly. So the match degree of Question Marks $F_{s}^{3 j}$ can also be calculated by $\gamma_{3 j}-\beta_{3 j}$ and the value of $\gamma_{3 j}-\beta_{3 j}$ is larger and the match degree is higher. In order to make the match degree of a different business additive, the range of $F_{s}^{3}$ must be mapped to $[0,1]$. Due to $\gamma_{3 j} \in[0,1]$, the match degree of Stars $F_{s}^{3 j}$ is

$$
F_{s}^{3 j}=\left\{\begin{array}{lr}
\frac{1}{2}+\frac{\gamma_{3 j}-\beta_{3 j}}{2 \beta_{3 j}}, & \gamma_{3 j} \in\left[0,2 \beta_{3 j}\right], \\
1, & \gamma_{3 j}>2 \beta_{3 j} .
\end{array}\right.
$$

Because the market share of Dogs is small and cannot form a scope effect, the enterprises should reduce investment on Dogs, and the strategy of Dogs is divest. So the IS investment of Question Marks and Dogs should be as small as possible. Therefore, the match degree of Dogs $F_{s}^{4 j}$ is

$$
F_{s}^{4 j}=\left\{\begin{array}{lr}
\frac{1}{2}+\frac{\beta_{4 j}-\gamma_{4 j}}{2 \beta_{4 j}}, & \gamma_{3 j} \in\left[0,2 \beta_{4 j}\right], \\
0, & \gamma_{4 j}>2 \beta_{4 j} .
\end{array}\right.
$$

The match degree between IS and Strategy $F_{\mathrm{s}}$ is calculated by the arithmetic mean of match degrees of these four type businesses. That is,

$$
F_{s}=\frac{1}{N} \times\left(\sum_{j=1}^{N_{1}} F_{s}^{1 j}+\sum_{j=1}^{N_{2}} F_{s}^{2 j}+\sum_{j=1}^{N_{3}} F_{s}^{3 j}+\sum_{j=1}^{N_{4}} F_{s}^{4 j}\right) .
$$

According to (5) and (14), the synergy degree between IS and corporate strategy SE can be denoted as:

$$
\mathrm{SE}=\alpha I_{s}+\beta F_{s},
$$

where $\alpha$ is the influence coefficient of suitability of the corporate strategy on the synergy degree; $\beta$ is the influence coefficient of suitability of the corporate strategy on the synergy degree, and the values of $\alpha$ and $\beta$ are set in accordance with specific conditions of enterprises. 
The range of SE is from 0 to 1 , and the closer the value of $\mathrm{SE}$ is to 1 , the higher the synergy degree between IS and corporate strategy is. When the synergy degree is higher, the synergy relationship between an IS and strategy plays greater role in promoting the formation of the core competitiveness of the enterprises and the realized IS value is bigger.

\section{Case study}

The data of products sale revenue and relative investment of some enterprises is shown in Table 2.

Table 2 . The sale revenue and investment classified by a product

\begin{tabular}{|c|c|c|c|c|}
\hline Product & $\begin{array}{c}\text { Sale revenue } \\
\text { of } 2011\end{array}$ & $\begin{array}{c}\text { Sale revenue } \\
\text { of 2012 }\end{array}$ & $\begin{array}{c}\text { Sale revenue of the } \\
\text { biggest competitors }\end{array}$ & $\begin{array}{c}\text { IS } \\
\text { investment }\end{array}$ \\
\hline Carbon steel products & 100 & 115.80 & 82 & 5 \\
\hline Alloy steel casts & 83.6 & 94.10 & 28 & 5 \\
\hline Engine iron casts & 34.2 & 36.30 & 9.8 & 2 \\
\hline Compressor iron casts & 38.7 & 40.60 & 16.8 & 1.5 \\
\hline Other iron casts & 45.3 & 47.60 & 21.6 & 0.5 \\
\hline Mold manufacturing & 20.6 & 21.00 & 20.6 & 1 \\
\hline Machining & 25.1 & 25.90 & 31.3 & 0 \\
\hline
\end{tabular}

Calculating the market growth rate and relative market share of each product from Table 2 determines the type of each product. According to (1)-(4), other parameters of each product are calculated and shown in Table 3.

Table 3. Type and parameters of each product

\begin{tabular}{|c|r|r|r|r|r|r|}
\hline Product & $\begin{array}{c}\text { Market } \\
\text { growth } \\
\text { rate }\end{array}$ & $\begin{array}{c}\text { Market } \\
\text { share }\end{array}$ & Type & $\begin{array}{c}\text { Ratio of } \\
\text { sale } \\
\text { revenue }\end{array}$ & $\begin{array}{c}\text { Ratio of } \\
\text { desired } \\
\text { investment }\end{array}$ & $\begin{array}{c}\text { Ratio of IS } \\
\text { investment }\end{array}$ \\
\hline Alloy steel casts & $13 \%$ & 2.99 & Stars & $24.68 \%$ & $17.40 \%$ & $33.33 \%$ \\
\hline Engine iron casts & $6 \%$ & 3.49 & $\begin{array}{c}\text { Cash } \\
\text { Cows }\end{array}$ & $9.52 \%$ & $5.41 \%$ & $13.33 \%$ \\
\hline $\begin{array}{c}\text { Compressor iron } \\
\text { casts }\end{array}$ & $5 \%$ & 2.30 & $\begin{array}{c}\text { Cash } \\
\text { Cows }\end{array}$ & $10.65 \%$ & $9.07 \%$ & $10.00 \%$ \\
\hline Other iron casts & $5 \%$ & 2.10 & $\begin{array}{c}\text { Cash } \\
\text { Cows }\end{array}$ & $12.48 \%$ & $11.69 \%$ & $3.33 \%$ \\
\hline $\begin{array}{c}\text { Carbon steel } \\
\text { products }\end{array}$ & $16 \%$ & 1.22 & $\begin{array}{l}\text { Question } \\
\text { Marks }\end{array}$ & $30.37 \%$ & $29.59 \%$ & $33.33 \%$ \\
\hline $\begin{array}{c}\text { Mold } \\
\text { manufacturing }\end{array}$ & $2 \%$ & 1.00 & Dogs & $5.51 \%$ & $10.50 \%$ & $6.67 \%$ \\
\hline Machining & $3 \%$ & 0.80 & Dogs & $6.79 \%$ & $16.34 \%$ & 0 \\
\hline
\end{tabular}

The suitability of this enterprise strategy $I_{s}$ is recording to (5), and:

$$
\begin{gathered}
\because \sum_{j=1}^{N_{1}} a_{1 j}=17.40 \%<\sum_{j=1}^{N_{3}} a_{3 j}=29.59 \%<\sum_{j=1}^{N_{1}} a_{1 j}+\sum_{j=1}^{N_{2}} a_{2 j}=43.57 \%, \\
\therefore I_{S}=17.40 \%+(5.41 \%+9.07 \%+11.69 \%)+29.59 \%=0.7316 .
\end{gathered}
$$


The match degree of each product belonging to Stars is

$$
F_{s}^{1 j}=\left\{\begin{array}{lr}
\frac{1}{2}+\frac{\gamma_{1 j}-\beta_{1 j}}{2 \beta_{1 j}}, & \gamma_{1 j} \in\left[0,2 \beta_{1 j}\right], \\
1, & \gamma_{1 j}>2 \beta_{1 j} .
\end{array}\right.
$$

The match degree of each product belonging to Cash Cows is

(17) $F_{s}^{2 j}= \begin{cases}1-\frac{\left|\gamma_{2 j}-\beta_{2 j}\right|}{\beta_{2 j}}, & \gamma_{2 j} \in\left[0,2 \beta_{2 j}\right], \quad \therefore F_{s}^{21}=1, F_{s}^{22}=0.9, F_{s}^{23}=0.29, \\ 0, & \gamma_{2 j}>2 \beta_{2 j} .\end{cases}$

The match degree of each product belonging to Question Marks is

$$
F_{s}^{3 j}=\left\{\begin{array}{lc}
\frac{1}{2}+\frac{\gamma_{3 j}-\beta_{3 j}}{2 \beta_{3 j}}, & \gamma_{3 j} \in\left[0,2 \beta_{3 j}\right], \quad \therefore F_{s}^{31}=0.56, \\
1, & \gamma_{3 j}>2 \beta_{3 j} .
\end{array}\right.
$$

The match degree of each product belonging to Dogs is

$$
F_{s}^{4 j}=\left\{\begin{array}{lc}
\frac{1}{2}+\frac{\beta_{4 j}-\gamma_{4 j}}{2 \beta_{4 j}}, & \gamma_{3 j} \in\left[0,2 \beta_{4 j}\right], \\
0, & \gamma_{4 j}>2 \beta_{4 j} .
\end{array}\right.
$$

The match degree between IS and corporate strategy is

$$
\begin{gathered}
F_{s}=\frac{1}{N} \times\left(\sum_{j=1}^{N_{1}} F_{s}^{1 j}+\sum_{j=1}^{N_{2}} F_{s}^{2 j}+\sum_{j=1}^{N_{3}} F_{s}^{3 j}+\sum_{j=1}^{N_{4}} F_{s}^{4 j}\right)= \\
=\frac{1}{7} \times(0.96+1.00+0.90+0.29+0.56+0.68+1.00)=0.77 .
\end{gathered}
$$

In the questionnaires of the enterprise staff, $62 \%$ of respondents thought the suitability of the strategy itself is more important, while the remaining $3 \%$ thought the match degree is more important, so that in (15) the value of $\alpha$ is 0.62 and the value of $\beta$ is 0.38 .

In this way the synergy degree between IS and corporate strategy is as follows:

$$
\mathrm{SE}=\alpha I_{s}+\beta F_{s}=0.62 \times I_{s}+0.38 \times F_{s}=0.7461 \text {. }
$$

Nowadays, the focus of this enterprise informatization is cast steel business and cast iron business which is the largest share of the enterprise total output, while other business, incapable in profitability, was not integrated into the enterprise informatization. So the positive effects of IS on the business goals is significant. The value of the synergy degree calculated by (15) coincides with the actual situation of synergy relationship between an IS and corporate strategy. 


\section{Conclusion}

Although IS cannot already form core competence alone, IS can promote the formation of the core competitiveness and realization of IS value by forming synergy relationship between an IS and corporate strategy. Because IS technology has newer rate of development, the key of forming synergic relationship between IS and corporate strategy is the supportive effect of IS on strategy, rather than the promotive effect of IS on a corporate strategic change. Based on BCG GrowthShare Matrix, the evaluation model of the synergy degree between an IS and corporate strategy, which considers the match degree between IS and strategy, and the suitability of the corporate current strategy, can indicate the synergy relationship, objectively reflect the realization of the IS value, and promote the optimization and upgrading of the enterprise IS construction.

Acknowledgements: This work was financially supported by the Fundamental Research Funds for the Central Universities (2013JBM037, 2013JBM150), and the Research Fund for the Doctoral Program of Higher Education of China (2011000911033, 20120009120046).

\section{References}

1. M o r r i s o n, A., R. Wensley. Boxing up or Boxed in? A Short History of the Boston Consulting Group Share/ Growth Matrix [J]. - Journal of Marketing Management, Vol. 2, 1991, No 7, 105-129.

2. B a r n e y, J. Firm Resource and Sustained Competitive Advantage [J]. - Journal of Management, Vol. 17, 1991, No 1, 99-120.

3. В ü y ü k ö z k a n, G. An Organizational Information Network for Corporate Responsiveness and Enhanced Performance [J]. - Journal of Manufacturing Technology Management, Vol. 1, 2004, No 15, 57-67.

4. Hitt, L., E. Bry n j olf s s o n. The Three Faces of IT Value: Theory and Evidence [J]. - In: Proceedings of 15th International Conference on Information Systems, 1994, No 11, 263-277.

5. Q u n, L i. Corporate Strategic Management [M]. BeiJing, China Railway Publishing House, 2000.

6. Tallon, P. P., L. K. Kenneth, V. Gurbaxani. Executives' Perceptions of the Business Value of Information Technology: A Process-Oriented Approach [J]. - Journal of Management Information Systems, Vol. 4, 2000, No 16, 145-173.

7. I r e l a n d, R. D., R. H o s k i s s o n, M. H it t. The Management of Strategy: Concepts and Cases. South-Western Cengage Learning, 2011.

8. Shen, Jingqi. Core Competencies and Corporate Strategy Analysis [J]. - Friends of Accounting, Vol. 9, 2006, 70-71.

9. Shen, Jisheng. Necessity and Way to Actualize Enterprise Strategy Management [J]. Railway Construction Technology, Vol. 6, 2005, 63-65.

10. Tilokavichai, V., P. Sophatsathit. An Organization-Wide Analysis of ERP and Information Systems Interrelationship for Logistics Support [J]. - Journal of System and Management Sciences, Vol. 1, 2011, No 1,70-81.

11. S h a o p ing, Z. Corporate Strategy Management Frame and the Way of Strategic Change [J]. Modern Business, Vol. 23, 2008, 68-69.

12. W e n-J i e, Z. On Corporate Capability and Corporate Strategic Alliance [J]. - Journal of Zhongnan University of Economics and Law, Vol. 4, 2008, 112-116. 